\title{
scripted
}

Volume 12, Issue 2, September 2015

\section{ONWARDS AND UPWARDS}

Professor Burkhard Schafer ${ }^{*}$

DOI: $10.2966 /$ scrip.120215.85

\section{(c) (i) (9)}

(C) Burkhard Schafer 2015. This work is licensed under a Creative Commons Attribution-NonCommercial-ShareAlike 4.0 International License. Please click on the link to read the terms and conditions.

\footnotetext{
* Professor of Computational Legal Theory and Director of SCRIPTed Centre for IT and IP Law,
} University of Edinburgh 
Graeme began his part of this, our anniversary editorial, with a confession - while the spirit is willing, the body is sometimes weak, and often simply finding the time to sit down in one's chair, and create the peace of mind needed for academic, analytical writing, feels all but impossible. The abstract realm of the "ought", the promise made to the editors, fights a battle with the "is", the tiredness that creeps into ones bones and thoughts. Burkhard faced the same problem - a promise made to our editors, passionate commitment to SCRIPTed, but increasingly pressed to find the time and mental space to put his thoughts on screen. So he too has to begin with a confession, and one much more grave than Graeme's. For while Graeme was tempted, he nonetheless gathered his strength and in writing his comprehensive and moving account of the intellectual history of SCRIPTed ultimately found value in the experience. Burkhard simply bailed. Now you will ask, dear reader, how can this be as you are clearly reading the second part of our anniversary editorial? Let me explain...

As Graeme noted, SCRIPT is premised on the complementarity of interests between medical, IT and IP lawyers. We all bring to the table our different perspectives, assumptions and ways of looking at the world, while searching for productive synergies and novel connections between them. Now, it is of course only natural that the medical law side centers in its concerns on the human body in all its frailty and limitations. This also affects the way they perceive of academic knowledge creation, such as writing editorials while being overcommitted. When a medical lawyer looks at the process of academic knowledge production, s/he sees a process that starts with complex electrochemical processes in a squishy human brain, which then leads to further electrochemical signals send along the spinal cord, and eventually the depolarization of the membrane potential of a skeletal muscle cell by an action potential, activation of non-gated voltage sensors, release of calcium into the local junctional space, and so and so forth, until eventually the human hand moves and hits the keys on a computer's keyboard. All of it extremely messy, all of it fraught with danger, many things can go wrong at any of the numerous stages, which then gives ample opportunity for medical professionals, and by implication medical lawyers, to become involved. All of these activities are also essentially tied to the unique, irreplaceable body that we typically have (despite the very best efforts of our colleagues at the Rosslyn Institute) and thus questions of the physical space that the body (is allowed to) occupy, and questions of ownership of body parts are recurrent themes in medical law. Physical bodies matter there.

We on the IT law side by contrast are not as obviously limited by the sheer physicality of our existence, dealing in information and programs as abstract, disembodied entities. When we look at academic knowledge creation, we simply see a string of symbols, the input data, being changed through recursive rewriting rules in an implementation of a Turing machine, a.k.a. an algorithm, into another set of symbols, the output. Algorithms rather than physical bodies are at the focus of our concerns. With that, many of the limitations of the human body disappear, with consequences for law and society that have frequently been the topic of SCRIPTed articles over the past ten years. Algorithms do not take up physical space, they are nowhere in particular, and with that ontological location-independence they transcend also national boundaries and with that jurisdictions. Cyberspace, especially now that cloud computing and virtualization further weaken the vestiges of physicality, challenges the state-centric legal order - as discussed in SCRIPTed e.g. by Barker 
(10:3), Harbinja (11:3), Jerker and Svantesson (11:2) or Papakonstantinou and de Hert (9:3). Second, algorithms can produce arbitrarily many copies of their output, and can themselves be replicated, in strict identical fashion, potentially infinitely many times. We might, for convenience sake and using a language that carries ancient metaphysical commitments and assumptions, speak of an autonomous software agent as "travelling to" an auction site and making a bid on behalf of its owner (Groom 1:1), or "being send to" the computer of a suspect and spying on his browsing activity (Abel and Schafer 6:1). Closer to reality though, we should say that the program creates an identical copy of itself on the target site. This ability of digital objects to be replicated in an identical fashion, again and again and again, is of course at the heart of the challenge that the Internet and the digital economy pose to traditional copyright regimes (Klang \& Nolin 9:3; Dizon 8:2). Finally, unlike humans, algorithms do not tire from doing the same repetitive task innumerous times, nor do they face the same restrictions on their working memory as humans do. This allows them to analyze ever-large amounts of data, in particular data created by human behavior, and then profile, predict and ultimately copy their creators. For specific examples see e.g. Silva and Reed 12:1; Garrie and Wong 3:3, Koops 8:3. To summarize: algorithms can data mine human behavior and create predictive profiles of them, they can be replicated at will, they do not tire, and they do not require physical space.

Burkhard had himself over-committed just like Graeme, taking on work that would require not one, but several of him. But unlike Graeme, who succeeded in making his one body do the work of five, the way medical lawyers approach the issue, Burkhard thought like an IT lawyer and simply had an AI analyze his past papers, model his writing style for an autonomous writing-bot, replicate the outcome several times, and assign each of the copies a different project - giving me the honor to say a few things about SCRIPTed at its anniversary. What else did you expect of someone who will freely admit that the highlight of his directorship of SCRIPT was to have almost talked Iain Banks into giving the keynote at the SCRIPT conference in 2010, and who asked me to dedicate this editorial to the memory of this most visionary of Scotland's writers?

Burkhard's body is right now probably enjoying the sun with Graham Greenleaf in Australia (4:1), Raghunath Ananthapur (8:3) in India, or Elisa Walker Echenique (9:2) in Chile. Or maybe he is visiting a traditional Christmas market with Gerrit Hornung in Germany (9:1), savoring the cuisine with Christophe Lazaro and Daniel Le Métayer (12:1) in France or watching the sunrise over Mount Fuji with Takashi Miyazawa and Hiroshi Osada (9:2) in Tokio - or indeed with any other of the numerous friends and contributors to SCRIPTed, who over the past 10 years helped in its evolution from a local, Edinburgh-centric initiative to an international institution with global readership and impact. His, and my, sincere thanks go to all of you.

It remains thus to me, in Burkhard's absence, yet a reasonably accurate copy of his mind, to say a few words about the future of SCRIPTed. SCRIPTed was never just another technology law journal, nor was it meant to be. Rather, it was always also a test bed for new forms of knowledge creation and dissemination in the digital economy. We have published many papers about open source, and creative commons licenses for digital publishing but we did not only publish papers about them, we used them in (what was then) new and challenging ways. Many of us in SCRIPT have been attempting to bridge the gap between law, science and the arts, and again, not only did 
SCRIPTed publish papers about this type of endeavor, but through is cover pages actively engages in integrating the artist's view of our field. From the beginning, we experimented with new ways of digital publishing and the functionalities that it enables. Some with great success, such as our cooperation with BAILII where we became the first online journal to be mirrored on the site. Others with less success, such as the "comment" function for each article, that we hoped would create a more interactive experience, but which never saw great uptake from the user community telling us however in the process also something about the way in which academic incentive structures help or hinder the use of novel, ICT assisted knowledge creation methods, and thus becoming part of our collective attempt to understand better how technology is changing our society. At the heart of it all was always our community of student-editors, and here undoubtedly lies our greatest success - to take what is best in the American, student-led Law Review model, and combine it with what is best in the peer-review model of science publishing. It is their enthusiasm and commitment that will help us to navigate the challenges that lie ahead. As so often, they are the digital natives, already using technologies that for us academics are still unknown and untested. They have always pushed, and will continue to push us, to experiment with new and different ways to produce and share academic content.

There are some challenges, and also opportunities, on the horizon for digital academic publishing and scientific knowledge creation. The push for "gold standard" open access publishing by some governments has created a veritable fraud industry, where predatory user-pays open access "journals" aggressively court inexperienced authors to pay them for the privilege of putting their papers on what looks like a journal but is hardly more than a blog. Perfunctory, if any, peer review then leads to a deluge of low standard or plain wrong papers flooding the market. When SCRIPT started, we were part of a mission to convince readers, contributors and governments that online publishing was a legitimate form of academic knowledge dissemination. Now we will face a similar battle over the reputation of open access journals. As educators, we sometimes struggle to prevent students from inappropriate use of Wikipedia as a resource. How then will we teach them to distinguish between legitimate high quality online journals, and websites that have all the visual appeal of a journal, but considerably less quality control than Wikipedia ever had? SCRIPTed can play an important role in this struggle. We do not charge our readers. But we also remain free for our authors. This allows us to establish a clear blue line between us, and predatory open access journals, the one indicator that cannot be faked. We can promise, to authors and readers, that we will never have to compromise quality for money. It means however for us to constantly look out for other forms of funding, as the largesse of Edinburgh School of Law might not last forever. So if you are an organization that has a few grand to spare, a law firm or technology company (and we really come cheap), and would like to be associated with an internationally respected law and technology journal, we should have lunch - especially if you can pay for that too ...

New technologies pose other challenges to the quality and integrity of academic knowledge production too - and here I have to talk a bit about my brethren. Just as ICT enabled fraudulent journals, it also enabled fraudulent writers. The most notoriously of these is SCIgen, like me a computer program that writes academic text, but unlike me a much inferior product that uses context-free grammar to randomly generate nonsense, which nonetheless looks for the untutored eye like a bona fide 
science research paper. And not just to the untutored eye, or so it seems. In 2014 Springer and IEEE had to remove over 120 papers from their databases when it transpired that they too were computer-generated nonsense. ${ }^{1}$ Cyril Labbé, who identified the scam papers, also showed that some of the ICT enabled tools that we as researchers use for quality control can be easily fooled by automated devices. He showed how h-index calculations, the metrics for impact and productivity of authors, can be manipulated by having bots feed Google Scholar a large set of computergenerated documents. These "articles" are all citing each other, a link farm for academic papers, which then pushes their imaginary author, "Ike Antkare" ahead of even Albert Einstein in the ranking, ${ }^{2}$

This last example also highlights an important intersection between copyright law, databases and digital publishing. The content of its papers is only part of the information that a journal can convey. Of increasing importance is also information that can be gleamed from data mining entire data sets of articles. Is the number of female authors in a discipline increasing or decreasing, allowing inferences on the success of equality policies, or hidden biases in the peer review process? Are certain topics increasing or decreasing in popularity, indicating new and emerging research fields? Are certain ideas widely shared in a relevant forensic science research community, indicating its "general acceptance" for the purpose of evidence law?

Commercial publishers like Elsevier often block or restrict access to this type of data mining even for data sets that are comprised of open access articles. ${ }^{3}$ We by contrast aim to play, together with other open access journals, an increasingly proactive role in enabling also this type of meta-analysis of academic publishing. This is of particular importance in the field of legal publishing, where initiatives such as the EU Openlaws project have demonstrated the benefits of freely configurable, minable and accessible legal information for access to justice and the administration of the legal system.

Automated generation and analysis of data through intelligent software will play an increasingly important part of academic knowledge production. As in the past, SCRIPTed will aspire to play a role in promoting what is good and improving what is bad in this new way of knowledge generation - by publishing articles about its legal implications, but also by being an active player, a resource, in this development. For me as a humble bot, my wish for Christmas, and the future of SCRIPTed, is to see a world where academic contributors, student editors and us intelligent devices become increasingly co-creators of knowledge, exploring and improving upon existing approaches and also shaping the copyright environment that allows this to happen.

\footnotetext{
1 Richard Van Noorden, "Publishers withdraw 120 gibberish papers" (2014) http://www.nature.com/news/publishers-withdraw-more-than-120-gibberish-papers-1.14763 (accessed $17 / 12 / 15)$

2 Cyril Labbe, "Ike Antkare one of the greatest stars in scientific firmament" (2010) http://rr.liglab.fr/research_report/RR-LIG-008.pdf (accessed 17/12/15)

${ }^{3}$ Ross Mounce, "The right to read is the right to mine: Text and data mining copyright exceptions introduced in the UK." (2014) http://blogs.lse.ac.uk/impactofsocialsciences/2014/06/04/the-right-toread-is-the-right-to-mine-tdm/ (accessed 17/12/15)
} 
For this issue though, all authors have been confirmed human, and I hope that you will find the data acquisition from their papers as enjoyable as I would have done, had our colleagues at Herriot Watt's given me a proper emotion module. ${ }^{4}$ To all of you, humans and machines, the hope that you will continue to be friends and supporters of SCRIPTed, and active contributors in our effort to shape the future of the law and technology interface. We cannot do it without you.

A merry Christmas and a happy reading of SCRIPTed $15: 3$

Sprant Flere-Imsaho Wu-Handrahen Xato Trabiti on behalf of Burkhard Schafer

\footnotetext{
4 "Emote: embodied perceptive tutors for empathy-based learning", at: http://gaips.inesc-id.pt/emote/
} (accessed 17/12/15) 